\title{
Article \\ Controllable Synthesis of 1, 3, 5-tris (1H-benzo[d]imidazole-2-yl) Benzene-Based MOFs
}

\author{
Sanjit Gaikwad ${ }^{1,+}$, Ravi Kumar Cheedarala ${ }^{2,+}$, Ranjit Gaikwad ${ }^{1}$, Soonho Kim ${ }^{3, *}$ and Sangil Han ${ }^{1, *}$ \\ 1 Department of Chemical Engineering, Changwon National University, Changwon-Si 51140, Korea; \\ sanjitgaikwad29@jbnu.ac.kr (S.G.); ranjitgaikwad1989@gmail.com (R.G.) \\ 2 Department of Materials Science and Engineering, Ulsan National Institute of Science and \\ Technology (UNIST), 50 UNIST-gil, Ulju-gun, Ulsan 689-798, Korea; ravi@changwon.ac.kr \\ 3 Industry-University Cooperation Foundation, Changwon National University, Changwon-Si 51140, Korea \\ * Correspondence: shkims@changwon.ac.kr (S.K.); shan@changwon.ac.kr (S.H.) \\ + These authors contributed equally to this research work.
}

check for

updates

Citation: Gaikwad, S.; Cheedarala, R.K.; Gaikwad, R.; Kim, S.; Han, S. Controllable Synthesis of 1, 3, 5-tris (1H-benzo[d]imidazole-2-yl) Benzene-Based MOFs. Appl. Sci. 2021, 11, 9856. https://doi.org/10.3390/ app11219856

Academic Editors: Stephen David Worrall and Julia Linnemann

Received: 15 September 2021

Accepted: 19 October 2021

Published: 21 October 202

Publisher's Note: MDPI stays neutral with regard to jurisdictional claims in published maps and institutional affiliations.

Copyright: (c) 2021 by the authors. Licensee MDPI, Basel, Switzerland. This article is an open access article distributed under the terms and conditions of the Creative Commons Attribution (CC BY) license (https:/ / creativecommons.org/licenses/by/ $4.0 /)$.

\begin{abstract}
The growing interest in metal-organic frameworks (MOFs) in both industrial and scientific circles has increased in the last twenty years, owing to their crystallinity, structural versatility, and controlled porosity. In this study, we present three novel MOFs obtained from the 1, 3, 5-tris (1H-benzo[d]imidazole-2-yl) benzene (TIBM) organic linker. The formed TIBM crystal powders were characterized by scanning electron microscopy (SEM) to estimate the morphology of the particles, powder X-ray diffraction (XRD) to confirm the crystal structure, Brunauer-EmmettTeller (BET) method for structural analysis, and thermogravimetric measurements to examine the thermal stability. The TIBM-Cu MOF showed excellent $\mathrm{CO}_{2}(3.60 \mathrm{mmol} / \mathrm{g})$ adsorption capacity at 1 bar and $298 \mathrm{~K}$, because of the open $\mathrm{Cu}$ site, compared to TIBM-Cr (1.6 mmol/g) and TIBM$\mathrm{Al}(2.1 \mathrm{mmol} / \mathrm{g})$. Additionally, due to the high porosity $(0.3-1.5 \mathrm{~nm})$, TIBM-Cu MOF showed a considerable $\mathrm{CO}_{2} / \mathrm{N}_{2}$ selectivity (53) compared to TIBM-Al (35) and TIBM-Cr (10).
\end{abstract}

Keywords: $\mathrm{MOF}$; adsorption; $\mathrm{CO}_{2}$ capture; porous material; solvothermal synthesis

\section{Introduction}

The design and implementation of new porous materials for carbon dioxide $\left(\mathrm{CO}_{2}\right)$ separation by selective adsorption is a rapidly increasing research area, because of its importance in energy and environment-related applications [1-3]. The greenhouse effect responsible for global warming is mainly related to $\mathrm{CO}_{2}$ emissions. Globally, $\mathrm{CO}_{2}$ release is rapidly increasing because of the combustion of carbon-based fuels (oil, coal, and natural gas) and chemical reactions in petrochemical industries, steel, and cement [4]. Post-combustion $\mathrm{CO}_{2}$ capture is considered the most effective technique for minimizing $\mathrm{CO}_{2}$ emitted from industrial and energy-related sources. To this end, different technologies have been applied for $\mathrm{CO}_{2}$ capture, such as membrane separation $[5,6]$ liquid ammonia, and amine absorption $[7,8]$ and adsorption $[9,10]$. Membrane separation is not suitable to largescale applications because of its short lifetime, limited performance at low pressure, and poor stability in acid gas environments [11]. The absorption process has been extensively used in power plants, thanks to the high $\mathrm{CO}_{2}$ selectivity promoted by amine functional groups; however, substantial downsides include equipment corrosion, high energy intake, and toxic ammonia loss [12].

Several materials have been investigated for their promising $\mathrm{CO}_{2}$ capture and catalytic conversion properties, including supported silica [13,14], zeolites [15,16], metal oxides [17,18], bio-waste-derived carbons [19,20], metal-organic frameworks (MOFs) [21,22], porous carbons [23,24], and recently, a new class of porous materials, i.e., porous organic polymers (POPs). The last materials further encompass crystalline covalent organic frameworks (COFs) [25,26], triazine-based organic frameworks (CTFs) [27,28], conjugated microporous polymers (CMPs) $[29,30]$, porous aromatic frameworks (PAFs) [31-33], and 
hyper-cross-linked polymers (HCPs) [34,35]. Amongst the cited systems, MOFs have attracted significant attention, owing to their high surface area, pore volume, and surface functionality. Their unique crystal structure is composed of metal centers connected by organic linkers [36] that can be tuned to give rise to wide applications in gas storage [37-39], separation [39,40], drug delivery [41], and catalysis [42].

Generally, MOFs present high $\mathrm{CO}_{2}$ adsorption capacities $(2-5 \mathrm{mmol} / \mathrm{g})$ at $298 \mathrm{~K}$ and high pressure, while the $\mathrm{CO}_{2}$ capture capacity at below 1 bar is still challenging [42]. Therefore, many methods have been developed to obtain MOFs with improved adsorption capacity, such as metal doping in the metal-organic framework [43] and chemical functionalization with amine groups, such as polyethyleneimine (PEI) and tetraethylenepentamine (TEPA) [44-46]. Nevertheless, during the preparation, other aspects must be considered, such as recyclability, stability, and mild regeneration conditions. Researchers have highlighted alternative synthetic methods to modify MOFs stability, flexibility, and particle size $[47,48]$. The materials were prepared using a solvothermal method, which requires high-temperature treatment of metal salts and organic ligands in water or organic solvents [49]. Solvent properties, such as polarity and hydrophobic/hydrophilicity, affect the reaction mechanism. In particular, low-boiling-point solvents generate high vapor pressure under a reaction in a sealed reactor. The vapor pressure in a sealed reactor increases as the temperature increases, which causes the formation of a supercritical fluid, in which liquid and gas exist simultaneously. This supercritical-fluid phase improves the mixing of chemical reagents in the solvent, and causes product formation by crystallization, which does not normally occur. Hence, the use of low-volatility solvents increases the mobility of the dissolved ions and allows better mixing of the reagents [50-52]. The surface functionalities and structural topologies of MOFs are determined by various types of metal ions and the network-forming ligands. Concerning this, alteration in the functionality and structure of MOFs is achieved using different secondary building units (SBUs), specific functional groups, and multi-topic building blocks [53].

Several novel structures have been developed to improve the MOFs performance. Chen et al. proposed an NJU-Bai MOF with amide-functionalized carboxylate linkers and measured a significant improvement in $\mathrm{CO}_{2} / \mathrm{N}_{2}$ selectivity (166.7) at $298 \mathrm{~K}$ [54]. Wang et al. reported a covalent triazine framework (CTF) with N-heteroaromatic building blocks, which exhibited a $\mathrm{CO}_{2}$ capacity of $3.48 \mathrm{mmol} / \mathrm{g}$ at $273 \mathrm{~K}$ and 1 bar [55]. Suresh et al. studied an amide-functionalized microporous organic polymer (Am-MOP) with a $\mathrm{CO}_{2}$ capacity of $40 \mathrm{~mL} / \mathrm{g}$ at $195 \mathrm{~K}$ and 1 bar. To improve $\mathrm{CO}_{2}$ binding affinity, Zheng et al. introduced polar acylamide groups in the framework, and the obtained Porous Coordination Network (PCN) series MOF exhibited a $\mathrm{CO}_{2}$ capacity of $20-24 \mathrm{mmol} / \mathrm{g}$ at 20 bar and $298 \mathrm{~K}$ [56]. Martin Schroder and coworkers prepared a series of isoreticular MFM MOFs functionalized with amide group, among which MFM-126 showed an excellent $\mathrm{CO}_{2}$ adsorption capacity of $4.63 \mathrm{mmol} / \mathrm{g}$ at $298 \mathrm{~K}$ and 1 bar [56].

In this work, we report the preparation of novel MOFs consisting of 1, 3, 5-tris $(1 \mathrm{H}$ benzo[d]imidazole-2-yl) benzene (TIBM) as an organic linker and $\mathrm{Al}, \mathrm{Cr}$, and $\mathrm{Cu}$ as metal ions. The synthesis of the organic core integrated with imidazole rings, which possess secondary and tertiary amines, was crucial for the protonation of metal ions. In order to allow the correct metal incorporation and obtain high-quality materials, the imidazole rings of the ligand have to be equally distant and symmetrically anchored to the phenyl ring [57-62]. Additionally, the use of the TIBM linkers with different metal precursors affects the pore size and the $\mathrm{CO}_{2} / \mathrm{N}_{2}$ adsorption selectivity of the prepared system. In this regard, we synthesized three novel MOFs using different metal precursors (MOF-Al, MOF-Cr, and MOF- $\mathrm{Cu}$ ) for $\mathrm{CO}_{2}$ and $\mathrm{N}_{2}$ capture. The obtained materials were examined using FT-IR, X-ray powder diffraction (XRPD), scanning electron microscopy (SEM), and thermogravimetric analysis (TGA). The volumetric method was used for $\mathrm{CO}_{2}$ and $\mathrm{N}_{2}$ adsorption capacity measurements. 


\section{Results}

2.1. Characterization of the TIBM Based MOFs

2.1.1. Morphological Properties

$\mathrm{N}_{2}$ adsorption isotherms at $77 \mathrm{~K}$ (Figure 1a) were measured using a volumetric BET instrument (BELSORP-max, MicrotracBEL, Osaka, Japan) in order to characterize the structural properties of the MOFs. All the isotherms showed a typical Type I isotherm, corresponding to a microporous structure. The specific surface area and pore volume of the TIBM MOFs were determined by-the Brunauer Emmett Teller (BET) method. TIBM-Cr presented the largest surface area and pore volume among the other MOFs (Table 1). The pore size distribution of the TIBM MOFs was determined by the non-local density functional theory (NLDFT) method. TIBM-Cr MOFs showed the largest pore size range $(1.0-4.0 \mathrm{~nm})$, compared to TIBM-Cu $(0.3$ to $1.5 \mathrm{~nm})$ and TIBM-Al $(1.0$ to $3.0 \mathrm{~nm})$ (Figure S1b in Supporting Information). The majority of pores appeared at $2 \mathrm{~nm}$ for TIBM$\mathrm{Al}$ and TIBM-Cr, and at $1 \mathrm{~nm}$ for TIBM-Cu.

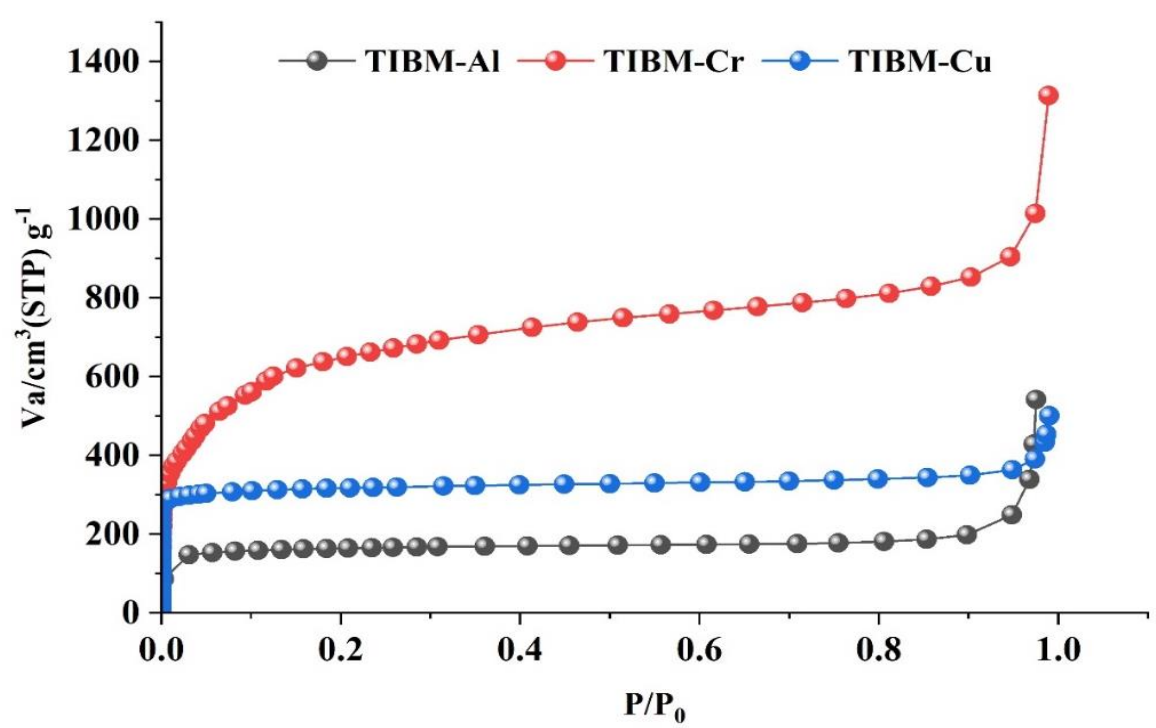

(a)

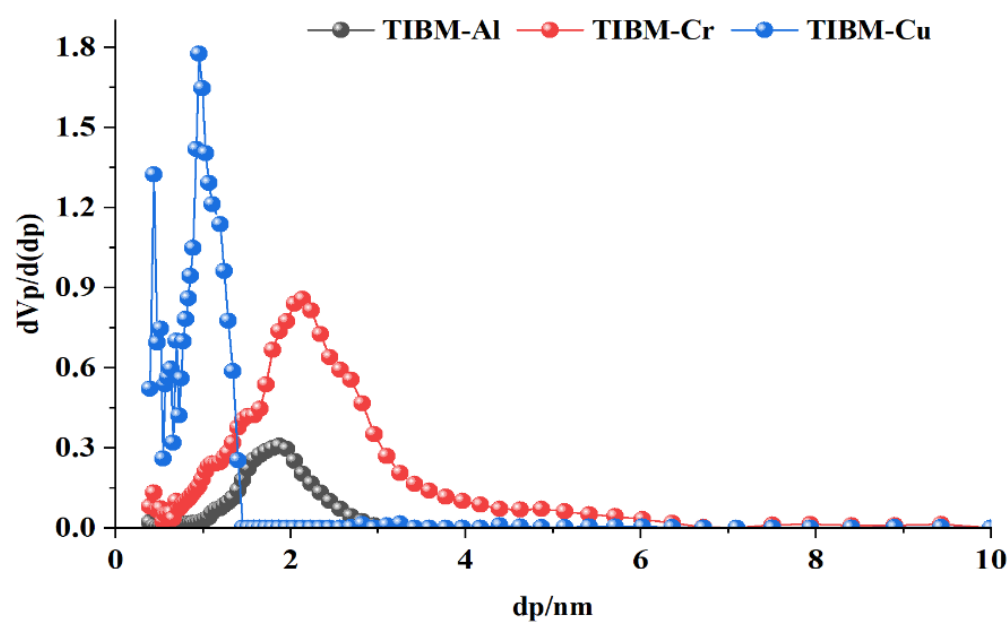

(b)

Figure 1. (a) $\mathrm{N}_{2}$ adsorption isotherms and (b) pore size distribution of TIBM-Al, TIBM-Cr, and MOF-Cu at $77 \mathrm{~K}$. 
Table 1. Surface area and pore volume of TIBM-MOFs.

\begin{tabular}{|c|c|c|}
\hline Sample Name & BET Surface Area $\left(\mathrm{m}^{2} / \mathrm{g}\right)$ & Total Pore Volume $\left(\mathrm{cm}^{3} / \mathrm{g}\right)$ \\
\hline TIBM-Al & 505.19 & 0.681 \\
\hline TIBM-Cr & 2141.1 & 2.116 \\
\hline TIBM-Cu & 1073.5 & 0.778 \\
\hline
\end{tabular}

Figure 2 reports the SEM images of the three TIBM MOF samples. The average particle diameters of the TIBM MOFs were determined using Image J software $(\mathrm{NIH}$, Bethesda, MD, USA) based on the pixel distance of each image, which is correlated with the scale bar. TIBM-Cr exhibited a smaller particle size $(0.25 \mu \mathrm{m})$ than TIBM-Cu $(28.29 \mu \mathrm{m})$ and TIBM-Al $(0.61 \mu \mathrm{m})$.
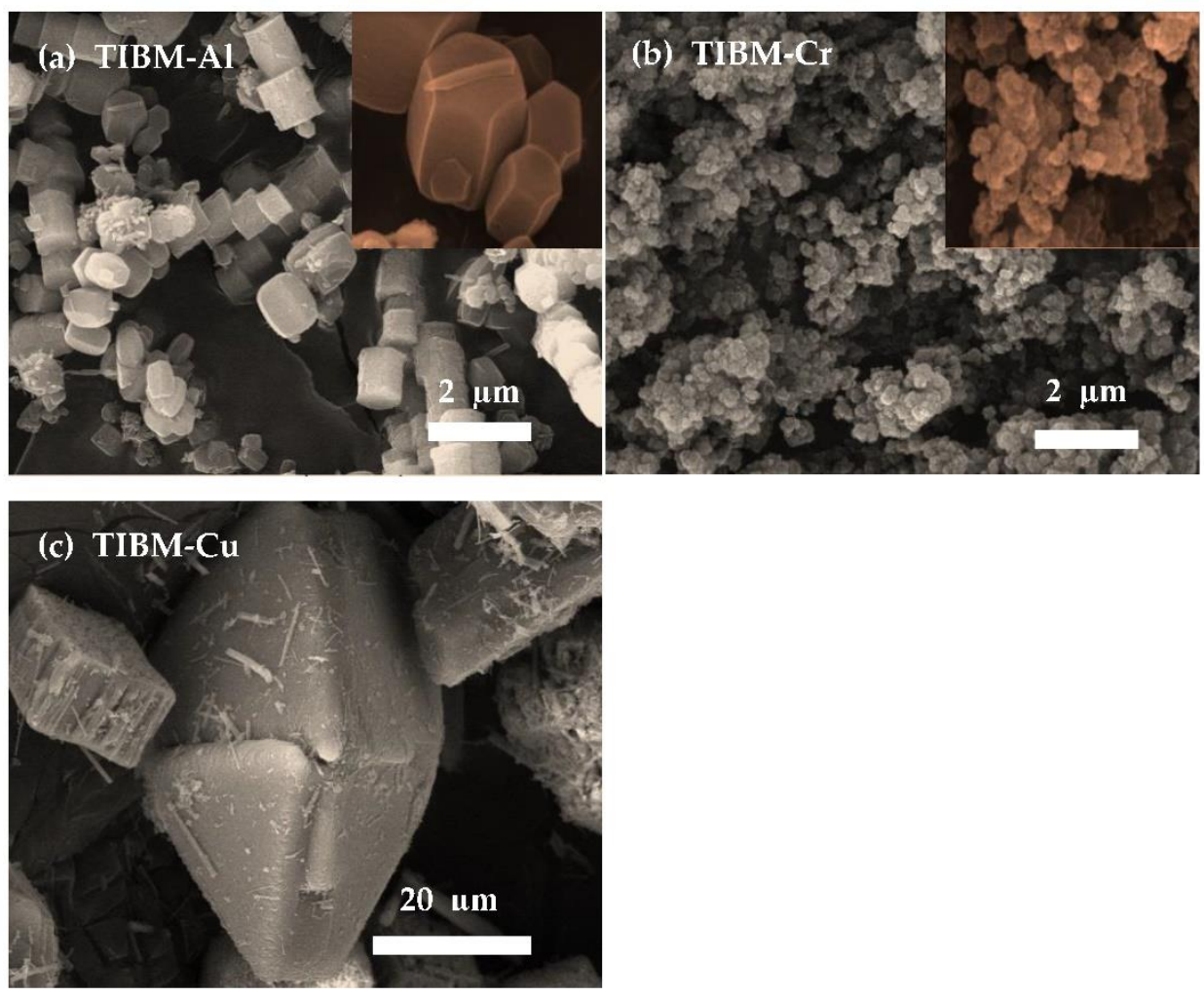

Figure 2. SEM images of (a) TIBM-Al, (b) TIBM-Cr, and (c) TIBM-Cu.

The MOF TIBM-Al showed a clear hexagonal crystal structure with sharp edges, spherical and highly porous nanoclusters were observed for TIBM-Cr, and a rhombic crystal structure was detected for TIBM-Cu. The TIBM-MOFs surfaces were found to be smooth, without evident cracks due to strong chelation between the central metal ion and TIBM amine linkers.

\subsubsection{X-ray Diffraction (XRD) Analysis}

The quality of TIBM-MOFs was optimized, and the samples were successfully doped with three metal ions by ionic-covalent bonds. The XRD pattern (Figure 3) of the TIBMMOFs was compatible with the simulated pattern of UiO-66 from the Cambridge Structural Database (CCDC 837796) [63]. The patterns of TIBM-Cu and TIBM-Al are consistent with those of Cu-BTC and HKUST-1, respectively, while for TIBM-Cr, a resemblance to that of MIL-101 (Fe) and Fe-BTC was found [64-71], thus confirming the successful synthesis and integrity of the crystal structure after the coordination with TIBM (Table 2). In particular, the chelation was indicated by a broad peak and a sharp peak at $2 \theta$ values of $9^{\circ}$ and $18^{\circ}$, 
respectively, providing clear evidence of the crystalline nature of the TIBM-Al MOF. The Cr-TIBM MOF exhibited blunt peak intensities at $2 \theta$ values of $10^{\circ}$ and $18^{\circ}-20^{\circ}$, showing an increase in the crystalline degree of the MOFs $[67,68]$. On the other hand, the Cu-TIBM MOF showed sharp crystalline peaks, comparable to those of the Cu-based MOFs $[64,65]$.

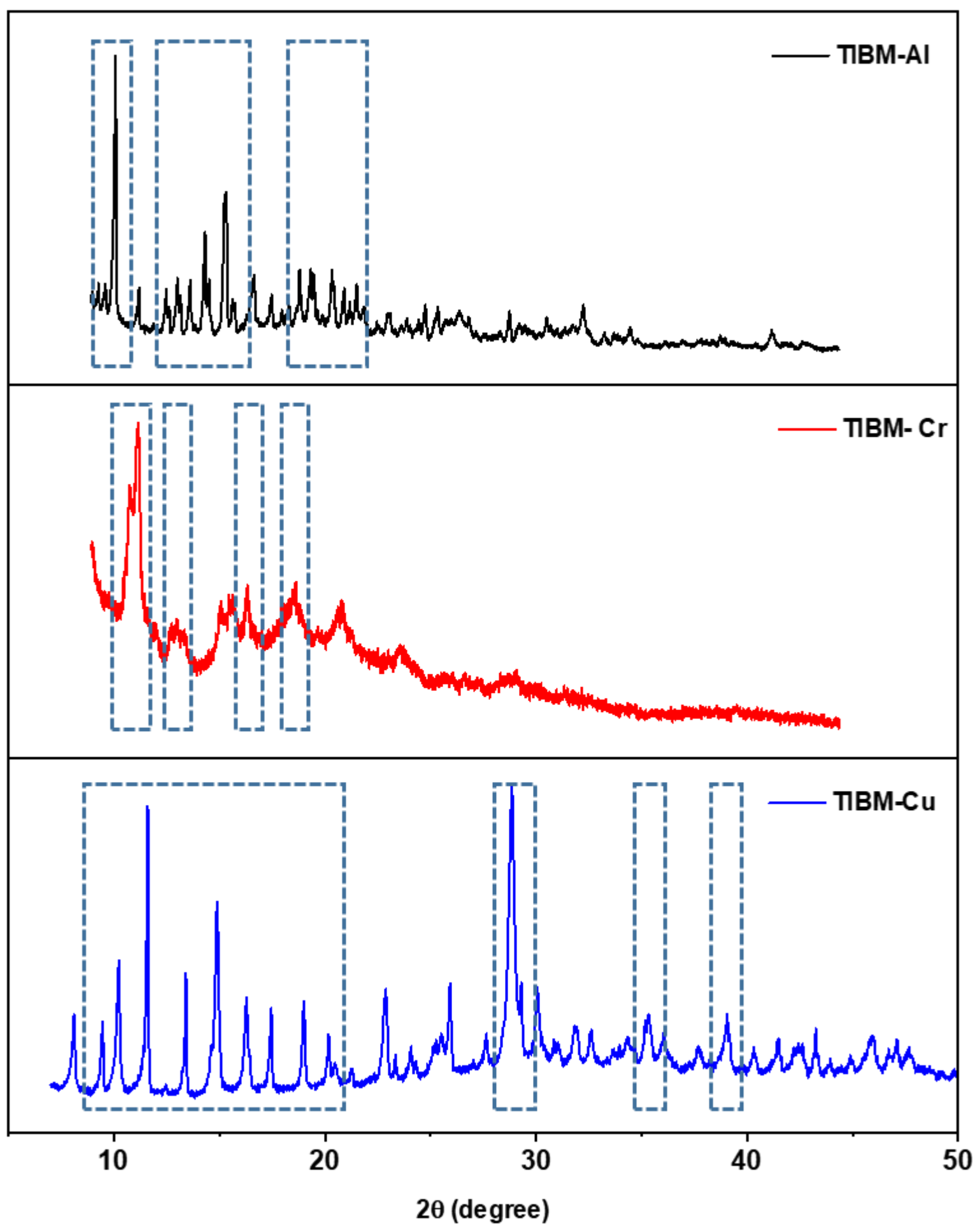

Figure 3. XRD patterns of MOF-Al, MOF-Cr, and MOF-Cu. (The dashed boxes represent the characteristic peaks that are matched with those of the reported MOFs). 
Table 2. Matching the characteristics peaks of TIMB MOFs with reported MOFs.

\begin{tabular}{cccc}
\hline Synthesized MOFs & Matching Peak Angles (20) & Reported MOFs with Matching Peaks & Known Structure \\
\hline TIBM-Al & $9.1,12.5-20,24-29$ & Cu-BTC, Ni-BTC $[67,68,72]$ & Hexagonal, cubic \\
\hline TIBM-Cu & $9.4-20,28.8,35.3,38.9$ & Cu-BTC, HKUST-1 [64,65] & Cubic, pyramidal \\
\hline TIBM-Cr & $10.9,14,20,24$ & Fe-BTC, MIL-100, MOF-235 [67-69,71,73] & Irregular spherical \\
\hline
\end{tabular}

\subsubsection{FTIR Analysis}

The FTIR analysis allowed characterizing molecular interactions and bonding formation in the MOF frameworks (Figure 4). The strong stretching bands at $490-500 \mathrm{~cm}^{-1}$ were attributed to metal-hydrogen bonds, particularly those of $\mathrm{Cr}$ and $\mathrm{Cu}$ metal ions. The bands at 720-724 $\mathrm{cm}^{-1}$ and $750-754 \mathrm{~cm}^{-1}$ correspond to $=\mathrm{C}-\mathrm{H}$ bond modes in phenyl rings $[74,75]$. The characteristic MOFs bands, related to metal-ion-bound second and third amines (>NH-M-N and $>\mathrm{N}-\mathrm{M}-\mathrm{N}$ of MOF), appear in the range $1090-1100 \mathrm{~cm}^{-1}$. Stretching bands due to $\mathrm{C}=\mathrm{C}$ and $\mathrm{C}-\mathrm{H}$ deformations of the phenyl rings were observed at $1399 \mathrm{~cm}^{-1}$. The strong vibration mode at $1455 \mathrm{~cm}^{-1}$ related to $-\mathrm{NH}$ and metal ions was attributed to the bidentate behavior of the N-M-N moiety. These characteristic peaks match well with the previously reported FTIR analysis of MOF-199 [28]. The strong resonance band exhibited by TIBM-Al was attributed to strong H-bonding of hydroxyl groups in the porous TIBM-Al material, as compared to TIBM-Cr and TIBM-Cu. This strong H-bonding occurs in Al-metal-based MOFs such as MIL-53(Al) and MIL-96 (Al), as compared to the Zn-based ZIF-8 and Zr-based UiO-66, and results in a strong resonance band [76-78]. The spectra for TIBM-Cr appear noticeably different after $3500 \mathrm{~cm}^{-1}$, as compared to TIBM-Al and TIBM-Cu. The small peaks that were observed in the TIBM-Al and TIBM-Cu spectra after $3500 \mathrm{~cm}^{-1}$ were attributed to the presence of crystalline water or the acidic -OH in carboxylic groups; these peaks do not appear in the case of TIBM-Cr [79,80]. The FTIR spectrum of the TIBM linker showed the typical peaks for $\mathrm{NH}$ wagging at $910 \mathrm{~cm}^{-1}$, for $\mathrm{C}=\mathrm{C}$ at $1420 \mathrm{~cm}^{-1}$, for $\mathrm{C}=\mathrm{N}$ at $1442 \mathrm{~cm}^{-1}$, and $1610 \mathrm{~cm}^{-1}$, for CO-NH at $1713 \mathrm{~cm}^{-1}$, and for $\mathrm{NH}$ at $3448 \mathrm{~cm}^{-1}$ (Figure $4 \mathrm{~b}$ ).

\subsubsection{Thermal Analysis}

During the TIBM MOFs thermogravimetric analysis (Figure 5), small drops in the range $50-150{ }^{\circ} \mathrm{C}$ were caused by dehydration. A further loss of $48 \%\left(300-500{ }^{\circ} \mathrm{C}\right)$ for TIBM-Cu, $28 \%\left(500-650{ }^{\circ} \mathrm{C}\right)$ for TIBM-Al, and $40 \%\left(400-600{ }^{\circ} \mathrm{C}\right)$ for TIBM-Cr, was ascribed to the decomposition of chelated imidazolium moieties [81,82]. According to the large drop temperatures, TIBM-Al presented better thermal stability than the other TIBM MOFs.

\section{2. $\mathrm{CO}_{2}$ and $\mathrm{N}_{2}$ Adsorption Measurements}

To examine the $\mathrm{CO}_{2}$-capture performance of all the samples, $\mathrm{CO}_{2}$ and $\mathrm{N}_{2}$ adsorption properties were measured at $298 \mathrm{~K}$ and $0-1$ bar. As reported in Figure 6, TIBM-Cu showed the highest $\mathrm{CO}_{2}$ adsorption capacity $(3.60 \mathrm{mmol} / \mathrm{g})$ at $1 \mathrm{bar}$, compared to the TIBM-Al $(2.04 \mathrm{mmol} / \mathrm{g})$ and TIBM-Cr $(1.67 \mathrm{mmol} / \mathrm{g})$. This result is ascribable to both the metal site exposure and the metal oxide chelation of the TIBM host precursor for $\mathrm{Cu}^{2+}$ ions [83]. The $\mathrm{Cu}-\mathrm{Cu}$ magnetic interaction of TIBM-Cu is stronger than the $\mathrm{Al}-\mathrm{Al}$ and $\mathrm{Cr}-\mathrm{Cr}$ magnetic interactions of TIBM-Al and TIBM-Cr, respectively, and results in a strong interaction between $\mathrm{CO}_{2}$ and the two available electrons of the $\mathrm{Cu}^{2+}$ metal in the TIBM-Cu MOF $[84,85]$. Conversely, TIBM-Cr showed the highest surface area $\left(2141.1 \mathrm{~m}^{2} / \mathrm{g}\right)$ and total pore volume $2.116 \mathrm{~cm}^{3} / \mathrm{g}$, compared to the other examined MOFs (Table 1), while a reverse adsorption trend was found for $\mathrm{N}_{2}$ adsorption for the TIBM MOFs. With regards to the $\mathrm{CO}_{2} / \mathrm{N}_{2}$ adsorption selectivity, which is defined as the ratio between $\mathrm{CO}_{2}$ adsorption capacity at 0.15 bar and $\mathrm{N}_{2}$ adsorption capacity at 0.85 bar, TIBM-Cu showed the highest value (53.69) compared to TIBM-Cr (11.16) and TIBM-Al (33.33), as reported in Figure 7, mainly in virtue of its high $\mathrm{CO}_{2}$ adsorption capacity, and concurrent low $\mathrm{N}_{2}$ adsorption capacity. In addition, $\mathrm{CO}_{2} / \mathrm{N}_{2}$ selectivity is different for each of the TIBM MOFs and depends on different factors, 
such as MOF pore size and available open metal sites for $\mathrm{CO}_{2}$. The pore sizes of TIBM-Cu $(0.5$ and $1 \mathrm{~nm})$ are more suited to selective adsorption of $\mathrm{CO}_{2}(0.33 \mathrm{~nm})$ over $\mathrm{N}_{2}(0.35 \mathrm{~nm})$ than TIMB-Al $(1.9 \mathrm{~nm})$ and TIBM-Cr $(2.2 \mathrm{~nm})$, owing to the size-selective separation. The $\mathrm{CO}_{2} / \mathrm{N}_{2}$ adsorption selectivity of TIBM-Cu is promising, compared to other MOFs reported in the literature (e.g., 6 for CuDABCO [86], 8 for ZIF-8 [87], 12 for MIL-101 (Cr) [88], 18 for MOF-5 [89], 16.5 for MOF-177 [89]). However, the adsorption capacities of the TIBM MOFs are comparable to those of previously reported MOFs (Table 3). TIBM-Cu was selected for the performance evaluation, showing that the $\mathrm{CO}_{2}$ adsorption capacity (Figure 8) gradually decreased with increasing temperature from 298 to $338 \mathrm{~K}$.

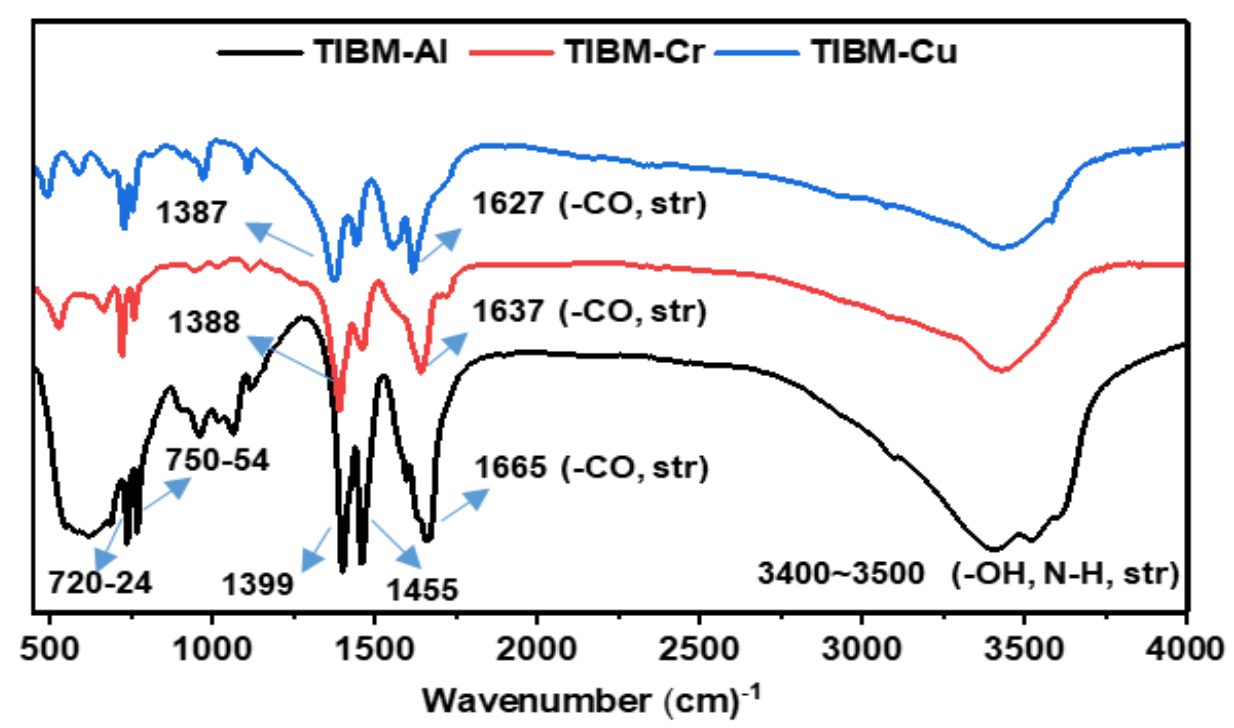

(a)

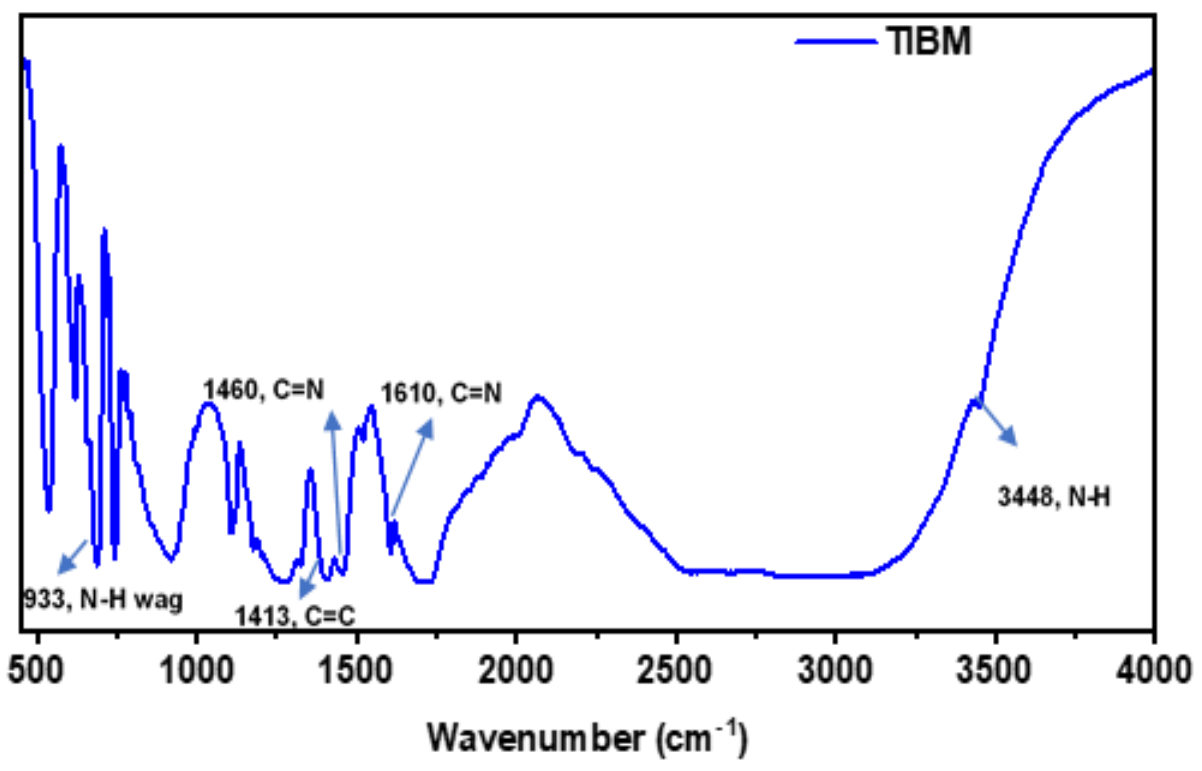

(b)

Figure 4. FTIR spectra of (a) TIBM-Al, TIBM-Cr, and TIBM-Cu, and (b) TIBM. 


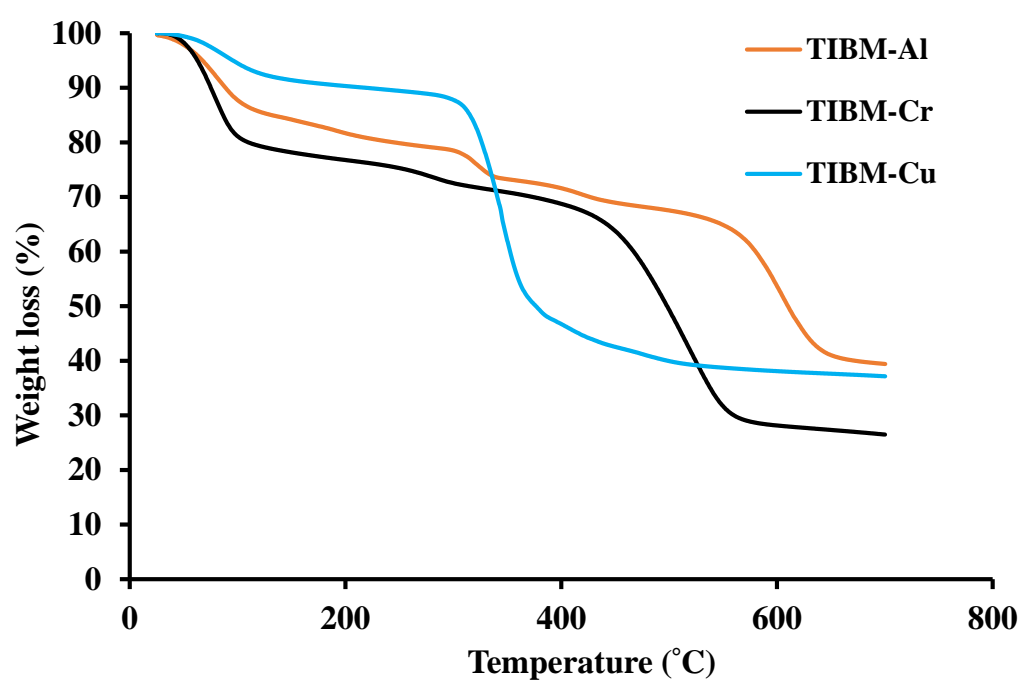

Figure 5. Thermal degradation graphs for TIBM-Al, TIBM-Cr, and TIBM-Cu.

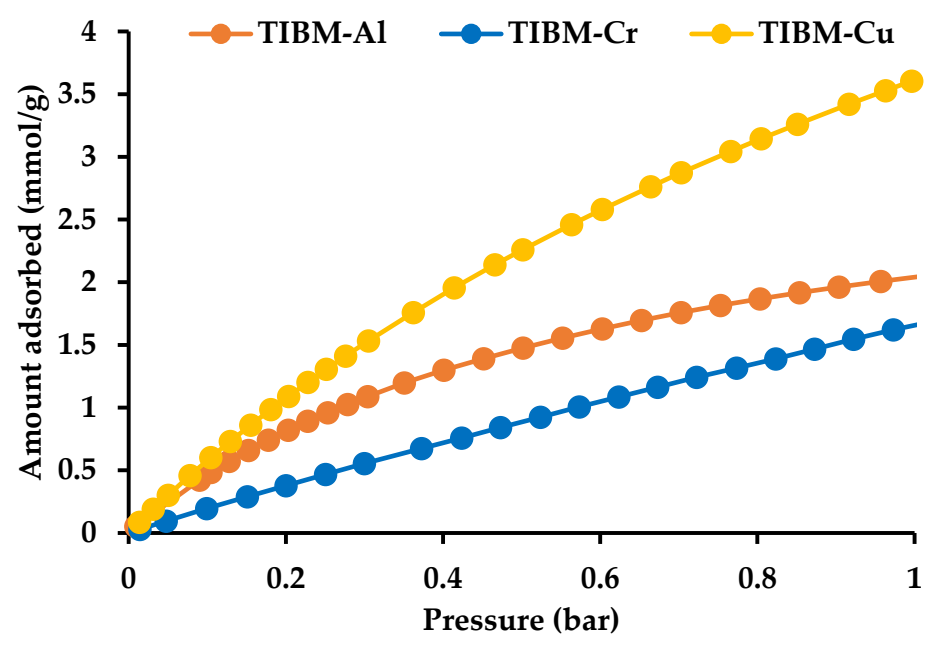

(a)

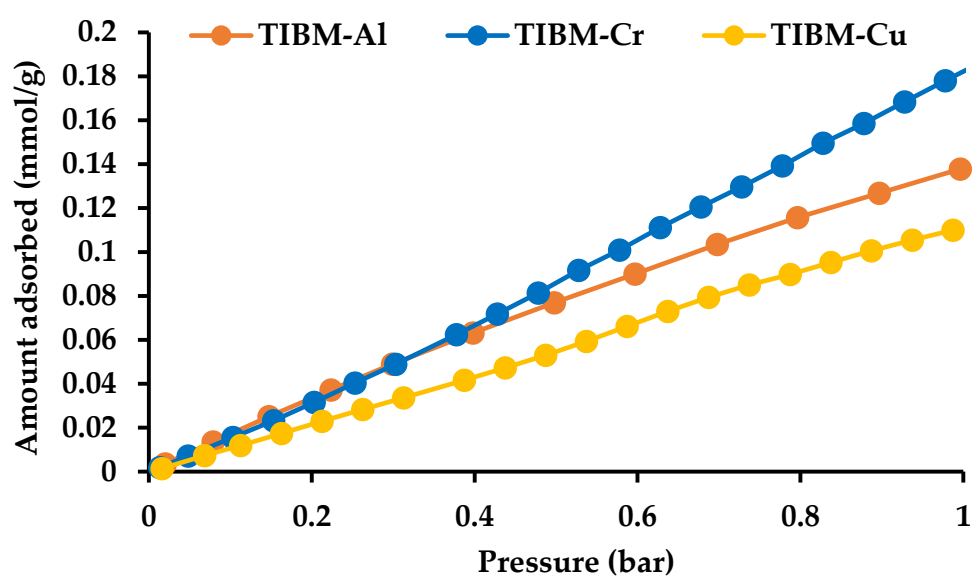

(b)

Figure 6. (a) $\mathrm{CO}_{2}$ and (b) $\mathrm{N}_{2}$ adsorption capacities at $298 \mathrm{~K}$ for TIBM-Al, TIBM-Cr, and TIBM-Cu MOFs. 


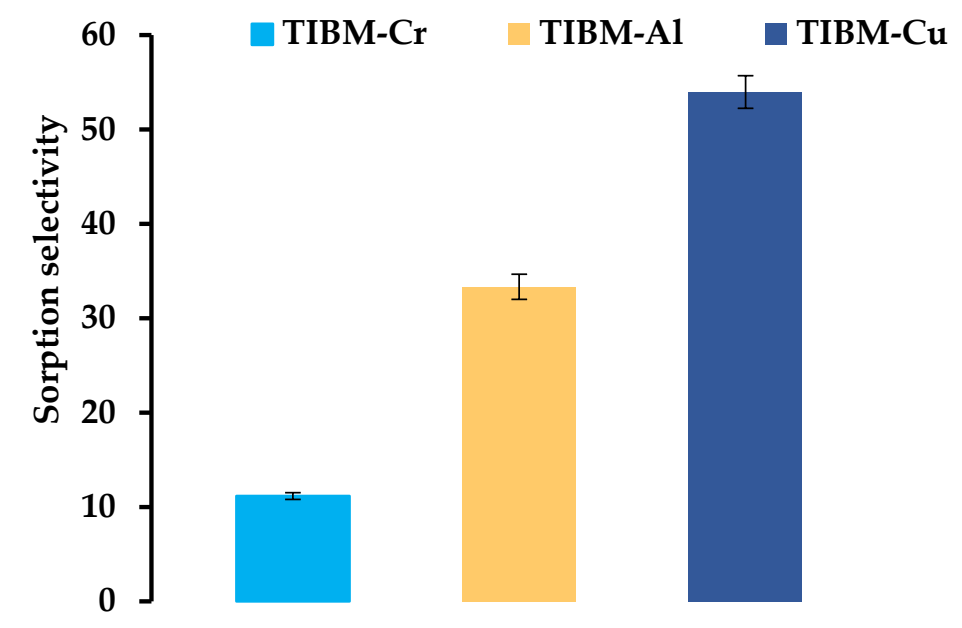

Figure 7. $\mathrm{CO}_{2} / \mathrm{N}_{2}$ selectivity for TIBM-Al, TIBM-Cr, and TIBM-Cu. Error bars represent the standard deviation $(n=3)$.

Table 3. $\mathrm{CO}_{2}$ adsorption capacities of different MOFs.

\begin{tabular}{|c|c|c|c|}
\hline Adsorbent & Condition (Temperature/Pressure) & $\mathrm{CO}_{2}$ Adsorption Capacity (mmol/g) & Reference \\
\hline TIBM-Cu & $298 \mathrm{~K} / 1$ bar & 3.6 & This work \\
\hline TIBM-Al & $298 \mathrm{~K} / 1$ bar & 2.0 & This work \\
\hline TIBM-Cr & $298 \mathrm{~K} / 1$ bar & 1.6 & This work \\
\hline IRMOF-74-III- $\left(\mathrm{CH}_{2} \mathrm{NH}_{2}\right)_{2}$ & $298 \mathrm{~K} / 1$ bar & 3 & [90] \\
\hline SNU-5 & $195 \mathrm{~K} / 1 \mathrm{bar}$ & 2.6 & [91] \\
\hline Fe-BTT & $298 \mathrm{~K} / 1$ bar & 3.1 & [92] \\
\hline$\left[\mathrm{Cd}_{2} \mathrm{~L} 1\left(\mathrm{H}_{2} \mathrm{O}\right)\right]_{2}$ & $293 \mathrm{~K} / 1 \mathrm{bar}$ & 2.1 & [93] \\
\hline$\left[\mathrm{Mg}(3,5-\mathrm{PDC})\left(\mathrm{H}_{2} \mathrm{O}\right)\right]$ & $298 \mathrm{~K} / 1$ bar & 0.6 & [94] \\
\hline$\left[\mathrm{Zn}_{4}(\mathrm{OH})_{2}(1,2,4-\mathrm{BTC})_{2}\left(\mathrm{H}_{2} \mathrm{O}\right)_{2}\right]$ & $295 \mathrm{~K} / 1$ bar & 1.9 & [95] \\
\hline $\mathrm{NH}_{2}-\mathrm{MIL}-125$ & $298 \mathrm{~K} / 1$ bar & 2.2 & [96] \\
\hline IRMOF-74-III- $\left(\mathrm{CH}_{2} \mathrm{NH}_{2}\right)_{2}$ & $298 \mathrm{~K} / 1$ bar & 3 & [90] \\
\hline IFMC-1 & $298 \mathrm{~K} / 1$ bar & 2.7 & [97] \\
\hline TMOF-1 & $298 \mathrm{~K} / 1$ bar & 1.4 & [98] \\
\hline MAF-23 & $298 \mathrm{~K} / 1$ bar & 2.5 & [99] \\
\hline USTC-253 & $298 \mathrm{~K} / 1$ bar & 2.1 & [100] \\
\hline$\left[\mathrm{Zn}\left(\mathrm{L}_{2}\right)\right]_{\mathrm{n}}$ & $298 \mathrm{~K} / 1$ bar & 2.1 & [101] \\
\hline USTC-253-TFA & $298 \mathrm{~K} / 1$ bar & 2.9 & [100] \\
\hline SNU-71 & $298 \mathrm{~K} / 1$ bar & 1 & [102] \\
\hline CPM-5 & $299 \mathrm{~K} / 1$ bar & 2.4 & [103] \\
\hline SNU-M10 & $298 \mathrm{~K} / 1$ bar & 2.1 & [104] \\
\hline $\mathrm{UiO}-66-\mathrm{SO}_{3} \mathrm{H}-0.15$ & $298 \mathrm{~K} / 1$ bar & 2.2 & [105] \\
\hline SHF-61 & $295 \mathrm{~K} / 1$ bar & 1 & [106] \\
\hline Cu-BTTri-ens & $298 \mathrm{~K} / 1$ bar & 1.3 & [107] \\
\hline SNU-31 & $298 \mathrm{~K} / 1$ bar & 0.6 & [108] \\
\hline UiO-66-AD4 & $298 \mathrm{~K} / 1$ bar & 1.9 & [109] \\
\hline
\end{tabular}




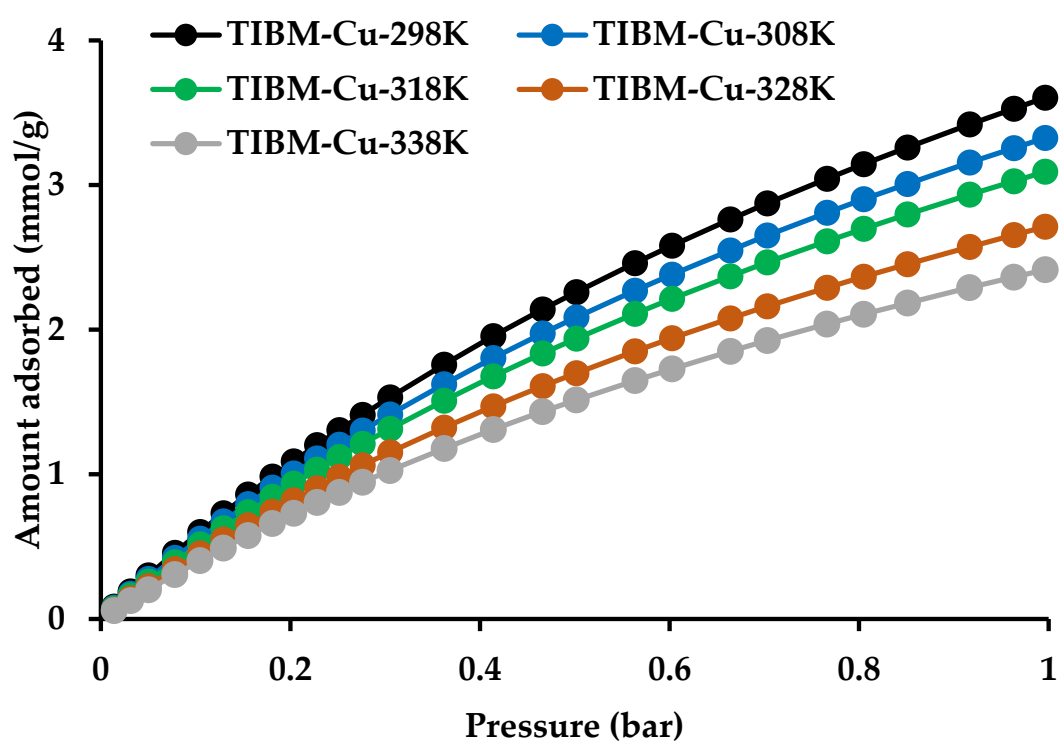

Figure 8. $\mathrm{CO}_{2}$ adsorption capacity of TIBM-Cu MOF at increasing temperatures.

\section{Materials and Methods}

\subsection{Chemicals}

All chemicals were used as received, without further purification. Trimesic acid, chromium nitrate nonahydrate (99\%), hydrofluoric acid (ACS reagent $\geq 48 \%$ ), deionized water, copper acetate (trace metals basis $\geq 99.99 \%$ ), ethanol (absolute alcohol $\geq 99.8 \%$ ), aluminum chloride hexahydrate (reagent plus $\geq 99 \%$ ), zinc acetate dihydrate (ACS reagent $\geq 98 \%$ ), N,N-dimethylformamide (anhydrous, $\geq 99.8 \%$ ), polyphosphoric acid (reagent grade), o-phenylenediamine ( $\geq 98 \%$ ), sodium bicarbonate solution (Bioreagent 7.5\%), and methanol (ACS reagent) were purchased from Sigma Aldrich (St. Louis, MO, USA).

\subsection{Preparation of 1, 3, 5-tris (1H-benzo[d]imidazole-2-yl) Benzene}

O-phenylenediamine $(7.2 \mathrm{~g}, 0.06 \mathrm{~mol})$ was added to a solution of trimesic acid $(4 \mathrm{~g}$, $0.03 \mathrm{mmol}$ ) in polyphosphoric acid (PPA) $(50 \mathrm{~mL})$, and the reaction mixture was heated at $230{ }^{\circ} \mathrm{C}$ for $12 \mathrm{~h}$ (Figure 9 ). The resultant yellowish-colored reaction mixture was poured into ice-cold water $(500 \mathrm{~mL})$; upon stirring, the obtained brown precipitate was collected. The precipitate was neutralized by adding $20 \%$ sodium bicarbonate solution and filtered by centrifugation (4000 rpm). The brown solid converted into a white solid ( $82 \%$ yield) after recrystallization with methanol [110]; Mp. $280^{\circ} \mathrm{C}$. 1H NMR (400 MHz, DMSO-d6/TMS, ppm) $\delta 7.24-7.52(\mathrm{~m}, 6 \mathrm{H}), \delta 7.62-7.92(\mathrm{~m}, 6 \mathrm{H}), 8.9(\mathrm{~s}, 3 \mathrm{H}), 13.2(\mathrm{~s}, 3 \mathrm{H}) ;{ }^{13} \mathrm{C}(100 \mathrm{MHz}$, DMSO-d $_{6 /}$ TMS, ppm) $\delta 115.2,119.2,122.2,123.3,125.5,131.6,135.8,144.2,159.1$; ESI-MS: $\left([\mathrm{M}+\mathrm{H}]^{+}\right) \mathrm{m} / \mathrm{z} 427.18(100 \%)$, found $\mathrm{m} / \mathrm{z} 427.32$ (100\%), Chemical Formula: $\mathrm{C}_{27} \mathrm{H}_{19} \mathrm{~N}_{6}{ }^{+}$, (Figure S1). The TIBM was synthesized as described in the literature [110]; the obtained pale yellow solid presented FT-IR and 1H-NMR spectra compatible with the ones previously reported [110,111].

\subsection{Synthesis of TIBM-Cr}

Chromium nitrate nonahydrate $(0.6340 \mathrm{~g})$ and TIBM $(0.438 \mathrm{~g})$ were dissolved in $20 \mathrm{~mL}$ deionized water by sonication for $10 \mathrm{~min}$, and hydrofluoric acid (HF) $(60 \mu \mathrm{L})$ was added to the mixture. The reaction mixture was transferred into a Teflon autoclave reactor sealed in a stainless steel vessel and maintained at $483 \mathrm{~K}$ for $48 \mathrm{~h}$. The fine green-colored precipitate was washed three times in hot ethanol and five times in hot water. The final TBIM-Cr MOF was dried at $373 \mathrm{~K}$ and evacuated at $423 \mathrm{~K}$ for $12 \mathrm{~h}$. 


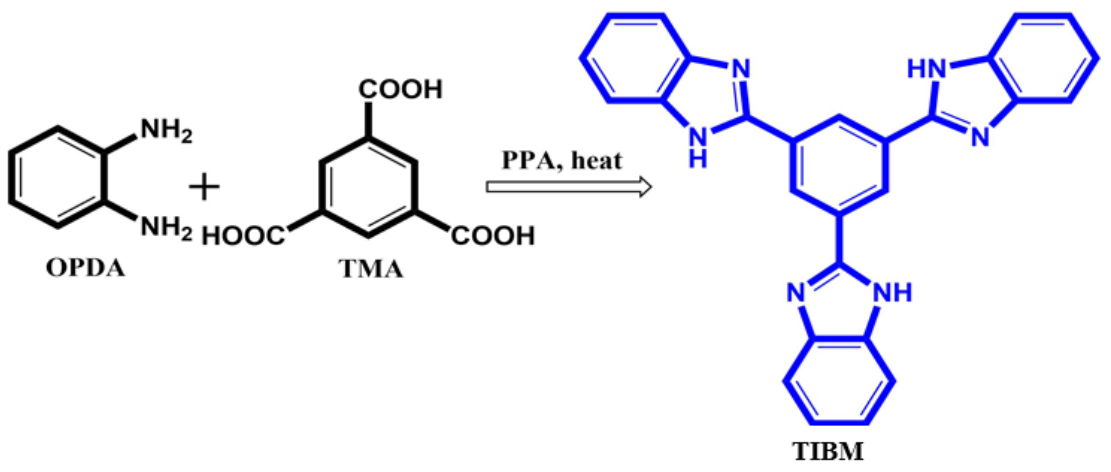

Figure 9. Synthesis of TIBM linker.

\subsection{Synthesis of TIBM-Cu}

Copper acetate $(1.4 \mathrm{~g})$ and TIBM $(0.78 \mathrm{~g})$ were dissolved in $30 \mathrm{~mL}$ water/ethanol (2:1) solution by sonication. HF $(120 \mu \mathrm{L})$ was added to the mixture as a module. The reaction mixture was transferred into a Teflon autoclave reactor sealed in a stainless-steel vessel and kept at $423 \mathrm{~K}$ for $24 \mathrm{~h}$. The blue-gray-colored precipitate was washed five times in ethanol and dried at $373 \mathrm{~K}$, and then evacuated at $393 \mathrm{~K}$ for $12 \mathrm{~h}$.

\subsection{Synthesis of TIBM-Al}

Aluminum chloride hexahydrate was dehydrated at $373 \mathrm{~K}$ for $10 \mathrm{~h}$ to remove water from the metal precursor. The dehydrated Al-metal precursor (1.2 g) and TIBM $(0.626 \mathrm{~g})$ were mixed in $30 \mathrm{~mL}$ water/ethanol (1:1) by sonication for $10 \mathrm{~min}$. HF $(60 \mu \mathrm{L})$ was added to the mixture as a module. The reaction mixture was transferred into a Teflon autoclave reactor sealed in a stainless-steel vessel, and maintained at $423 \mathrm{~K}$ for $48 \mathrm{~h}$. The white-colored powder precipitate was washed five times in ethanol, subsequently dried at $373 \mathrm{~K}$, and evacuated at $393 \mathrm{~K}$ for $12 \mathrm{~h}$ (Figure 10).

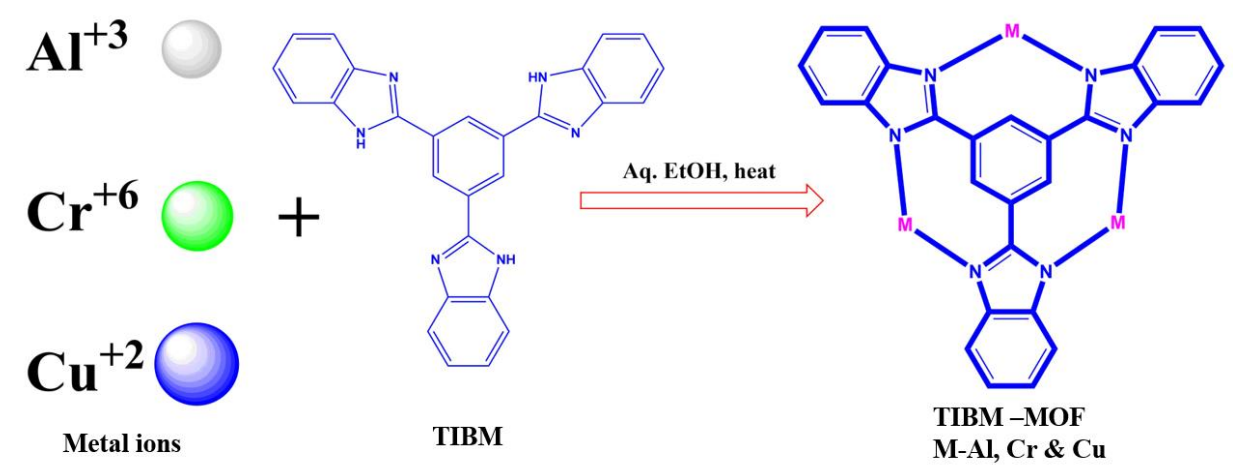

Figure 10. Synthesis of TIBM-MOFs (i.e., $\mathrm{M}=\mathrm{Al}, \mathrm{Cr}$, and $\mathrm{Cu}$ ).

\subsection{Characterization}

Fourier-transform infrared spectra (FTIR) in the range of $400-4000 \mathrm{~cm}^{-1}$ were obtained with a Spectrum Two, PerkinElmer, UK spectrometer. A mixture of TIBM MOF power and $\mathrm{KBr}$ in the weight ratio of 1:99 was used to prepare the sample. The TIBM-MOFs particle morphology and crystal size were determined by means of SEM (Merlin compact, Carl Zeiss) at an accelerating voltage of $1 \mathrm{kV} / 10 \mathrm{kV}$, with a current of $10 \mu \mathrm{A}$. A volumetric method was used to analyze morphological properties, such as specific surface area, pore size distribution, and pore volume, using a BELSORP-mini (Microtrac BEL, Osaka, Japan) based on $\mathrm{N}_{2}$ adsorption isotherm at $77 \mathrm{~K}$. XRD analysis (X'Pert Pro-MPD, PANalytical, Almelo, The Netherlands) was performed to determine the TIBM-MOFs crystallinity. 
For the thermal stability test, the samples were heated to $800{ }^{\circ} \mathrm{C}$ at a heating rate of $20{ }^{\circ} \mathrm{C} /$ min under $\mathrm{N}_{2}$ atmosphere $(50 \mathrm{~mL} / \mathrm{min}$ ), using a TGA instrument (Scinco TGA N1000, Twin Lakes, WI, USA). 1H-NMR spectra were obtained with a Bruker $400 \mathrm{MHz}$ $\mathrm{NMR}$ spectrometer in $\mathrm{CDCl}_{3}$, using tetramethylsilane (TMS) as an internal standard. Mass spectra were recorded on a Bruker Daltonik, Bremen, Germany, operated in linear mode with a pulsed nitrogen laser $(337 \mathrm{~nm}$, pulse frequency, $2 \mathrm{~Hz}$ ).

\section{7. $\mathrm{CO}_{2}$ and $\mathrm{N}_{2}$ Adsorption Capacity Measurements}

$\mathrm{CO}_{2}$ and $\mathrm{N}_{2}$ adsorption on TIBM-MOFs were measured at $298-338 \mathrm{~K}$ at the pressure of 0-1 bar using a volumetric apparatus (BELSORP-mini, MicrotracBEL, Osaka, Japan). TIBM MOFs were first evacuated at $393 \mathrm{~K}$ (TIBM-Cu, TIBM-Al) and $423 \mathrm{~K}$ (TIBM-Cr) for $12 \mathrm{~h}$, to remove impurities. A water circulating jacket connected to a thermostatic bath was used to control the measurement temperature with a precision of $\pm 0.01{ }^{\circ} \mathrm{C}$. A reference gas (helium) was used to determine the free space in the sample holder.

\section{Conclusions}

In summary, we have developed novel TIBM MOFs using a simple and inexpensive solvothermal process. The TIBM linker was prepared via condensation method, using trimesic acid and o-phenylenediamine. Interestingly, metal-modified TIBM MOFs (Cu-TIBM, Cr-TIBM, Al-TIBM) showed modifications in characteristic properties such as morphology, surface area, and pore size distribution. In particular, TIBM-Cu showed a remarkable $\mathrm{CO}_{2}$ adsorption capacity $(3.60 \mathrm{mmol} / \mathrm{g}$ ) and selectivity (53), compared to TIBM-Cr and TIBM-Al. Due to the presence of open metal sites, $\mathrm{N}$ atoms of the imidazole functional groups, and an ideal pore size $(0.3-1.5 \mathrm{~nm})$ for selective $\mathrm{CO}_{2}$ adsorption (the size of the pore aperture is similar to the size of $\mathrm{CO}_{2}$ ), the TIBM-Cu $\mathrm{CO}_{2}$ adsorption capacity is higher than that of previously reported MOFs, including MOF-5 (2.1 mmol/g), ZIF-8 (0.8 mmol/g), MIL-101 (Cr) $(1.8 \mathrm{mmol} / \mathrm{g})$ [112], MIL-101 (Cr, Mg) (2.0 mmol/g) [113], UiO-66 (2.5 mmol/g) [112], UiO-66- NH 2 (3 mmol/g) [114], and MOF$177(0.8 \mathrm{mmol} / \mathrm{g})[115,116]$. Moreover, the TIBM-Cr MOF high surface area $\left(2141 \mathrm{~m}^{2} / \mathrm{g}\right)$ and pore volume $\left(2.116 \mathrm{~cm}^{3} / \mathrm{g}\right)$ points to the material potential for further applications.

Supplementary Materials: The following figures are available online at https:/ / www.mdpi.com/ article/10.3390/app11219856/s1, Figure S1: NMR spectra of TIBM linker.

Author Contributions: Writing_original draft preparation, conceptualization, and methodology, S.G. and R.K.C.; validation, S.G. and R.G.; supervision and writing-review and editing, S.H. and S.K.; investigation and resources, S.K. All authors have read and agreed to the published version of the manuscript.

Funding: This research was supported by the Changwon National University from 2021 to 2022.

Data Availability Statement: Not applicable.

Acknowledgments: This research was supported by the Changwon National University from 2021 to 2022 .

Conflicts of Interest: The authors declare no conflict of interest.

\section{References}

1. Keith, D.W. Why capture $\mathrm{CO}_{2}$ from the atmosphere? Science 2009, 325, 1654-1655. [CrossRef]

2. Raupach, M.R.; Marland, G.; Ciais, P.; Le Quéré, C.; Canadell, J.G.; Klepper, G.; Field, C.B. Global and regional drivers of accelerating $\mathrm{CO}_{2}$ emissions. Proc. Natl. Acad. Sci. USA 2007, 104, 10288-10293. [CrossRef] [PubMed]

3. Canadell, J.G.; Le Quéré, C.; Raupach, M.R.; Field, C.B.; Buitenhuis, E.T.; Ciais, P.; Conway, T.J.; Gillett, N.P.; Houghton, R.; Marland, G. Contributions to accelerating atmospheric $\mathrm{CO}_{2}$ growth from economic activity, carbon intensity, and efficiency of natural sinks. Proc. Natl. Acad. Sci. USA 2007, 104, 18866-18870. [CrossRef] [PubMed]

4. Quadrelli, R.; Peterson, S. The energy-climate challenge: Recent trends in $\mathrm{CO}_{2}$ emissions from fuel combustion. Energy Policy 2007, 35, 5938-5952. [CrossRef] 
5. $\quad$ Ma, J.; Ying, Y.; Yang, Q.; Ban, Y.; Huang, H.; Guo, X.; Xiao, Y.; Liu, D.; Li, Y.; Yang, W. Mixed-matrix membranes containing functionalized porous metal-organic polyhedrons for the effective separation of $\mathrm{CO}_{2}-\mathrm{CH}_{4}$ mixture. Chem. Commun. 2015, 51, 4249-4251. [CrossRef]

6. Zou, X.; Zhang, F.; Thomas, S.; Zhu, G.; Valtchev, V.; Mintova, S. $\mathrm{Co}_{3}(\mathrm{HCOO})_{6}$ microporous metal-organic framework membrane for separation of $\mathrm{CO}_{2} / \mathrm{CH}_{4}$ mixtures. Chem. Eur. J. 2011, 17, 12076-12083. [CrossRef]

7. Conway, W.; Bruggink, S.; Beyad, Y.; Luo, W.; Melián-Cabrera, I.; Puxty, G.; Feron, P. $\mathrm{CO}_{2}$ absorption into aqueous amine blended solutions containing monoethanolamine (MEA), N, N-dimethylethanolamine (DMEA), N, N-diethylethanolamine (DEEA) and 2-amino-2-methyl-1-propanol (AMP) for post-combustion capture processes. Chem. Eng. Sci. 2015, 126, 446-454. [CrossRef]

8. Pinto, D.D.; Monteiro, J.G.-S.; Johnsen, B.; Svendsen, H.F.; Knuutila, H. Density measurements and modelling of loaded and unloaded aqueous solutions of MDEA (N-methyldiethanolamine), DMEA (N, N-dimethylethanolamine), DEEA (diethylethanolamine) and MAPA (N-methyl-1, 3-diaminopropane). Int. J. Greenh. Gas Control 2014, 25, 173-185. [CrossRef]

9. Zhao, H.; Luo, X.; Zhang, H.; Sun, N.; Wei, W.; Sun, Y. Carbon-based adsorbents for post-combustion capture: A review. Greenh. Gases Sci.Technol. 2018, 8, 11-36. [CrossRef]

10. Yu, J.; Xie, L.-H.; Li, J.-R.; Ma, Y.; Seminario, J.M.; Balbuena, P.B. CO 2 capture and separations using MOFs: Computational and experimental studies. Chem. Rev. 2017, 117, 9674-9754. [CrossRef]

11. He, X.J.E. A review of material development in the field of carbon capture and the application of membrane-based processes in power plants and energy-intensive industries. Energy Sustain. Soc. 2018, 8, 34. [CrossRef]

12. Lawal, O.; Bello, A.; Idem, R. The role of methyl diethanolamine (MDEA) in preventing the oxidative degradation of $\mathrm{CO}_{2}$ loaded and concentrated aqueous monoethanolamine (MEA)-MDEA blends during $\mathrm{CO}_{2}$ absorption from flue gases. Ind. Eng. Chem. Res. 2005, 44, 1874-1896. [CrossRef]

13. Jeong, W.; Kim, J. Understanding the mechanisms of $\mathrm{CO}_{2}$ adsorption enhancement in pure silica zeolites under humid conditions. J. Phys. Chem. C 2016, 120, 23500-23510. [CrossRef]

14. Ravi, S.; Kang, D.H.; Roshan, R.; Tharun, J.; Kathalikkattil, A.C.; Park, D.W. Organic sulphonate salts tethered to mesoporous silicas as catalysts for $\mathrm{CO}_{2}$ fixation into cyclic carbonates. Catal. Sci. Technol. 2015, 5, 1580-1587. [CrossRef]

15. Jee, S.E.; Sholl, D.S. Carbon dioxide and methane transport in DDR zeolite: Insights from molecular simulations into carbon dioxide separations in small pore zeolites. J. Am. Chem. Soc. 2009, 131, 7896-7904. [CrossRef]

16. Su, F.; Lu, C.; Kuo, S.-C.; Zeng, W. Adsorption of $\mathrm{CO}_{2}$ on amine-functionalized Y-type zeolites. Energy Fuels 2010, $24,1441-1448$. [CrossRef]

17. Koirala, R.; Gunugunuri, K.R.; Pratsinis, S.E.; Smirniotis, P.G. Effect of zirconia doping on the structure and stability of CaO-based sorbents for $\mathrm{CO}_{2}$ capture during extended operating cycles. J. Phys. Chem. C 2011, 115, 24804-24812. [CrossRef]

18. Wang, Q.; Tay, H.H.; Zhong, Z.; Luo, J.; Borgna, A. Synthesis of high-temperature $\mathrm{CO}_{2}$ adsorbents from organo-layered double hydroxides with markedly improved $\mathrm{CO}_{2}$ capture capacity. Energy Environ. Sci. 2012, 5, 7526-7530. [CrossRef]

19. Plaza, M.; González, A.; Pevida, C.; Pis, J.; Rubiera, F. Valorisation of spent coffee grounds as $\mathrm{CO}_{2}$ adsorbents for postcombustion capture applications. Appl. Energy 2012, 99, 272-279. [CrossRef]

20. Wang, J.; Heerwig, A.; Lohe, M.R.; Oschatz, M.; Borchardt, L.; Kaskel, S. Fungi-based porous carbons for $\mathrm{CO}_{2}$ adsorption and separation. J. Mater. Chem. 2012, 22, 13911-13913. [CrossRef]

21. Yu, J.; Balbuena, P.B. How impurities affect $\mathrm{CO}_{2}$ capture in metal-organic frameworks modified with different functional groups ACS Sustain. Chem. Eng. 2015, 3, 117-124. [CrossRef]

22. Hwang, G.-Y.; Roshan, R.; Ryu, H.-S.; Jeong, H.-M.; Ravi, S.; Kim, M.-I.; Park, D.-W. A highly efficient zeolitic imidazolate framework catalyst for the co-catalyst and solvent free synthesis of cyclic carbonates from $\mathrm{CO}_{2}$. J. CO2 Util. 2016, 15, 123-130. [CrossRef]

23. Chen, J.; Yang, J.; Hu, G.; Hu, X.; Li, Z.; Shen, S.; Radosz, M.; Fan, M. Enhanced $\mathrm{CO}_{2}$ capture capacity of nitrogen-doped biomass-derived porous carbons. ACS Sustain. Chem. Eng. 2016, 4, 1439-1445. [CrossRef]

24. Wei, J.; Zhou, D.; Sun, Z.; Deng, Y.; Xia, Y.; Zhao, D. A controllable synthesis of rich nitrogen-doped ordered mesoporous carbon for $\mathrm{CO}_{2}$ capture and supercapacitors. Adv. Funct. Mater. 2013, 23, 2322-2328. [CrossRef]

25. Cote, A.P.; Benin, A.I.; Ockwig, N.W.; O’Keeffe, M.; Matzger, A.J.; Yaghi, O.M. Porous, crystalline, covalent organic frameworks. Science 2005, 310, 1166-1170. [CrossRef]

26. Furukawa, H.; Yaghi, O.M. Storage of hydrogen, methane, and carbon dioxide in highly porous covalent organic frameworks for clean energy applications. J. Am. Chem. Soc. 2009, 131, 8875-8883. [CrossRef]

27. Ren, S.; Bojdys, M.J.; Dawson, R.; Laybourn, A.; Khimyak, Y.Z.; Adams, D.J.; Cooper, A.I. Porous, fluorescent, covalent triazine-based frameworks via room-temperature and microwave-assisted synthesis. Adv. Mater. 2012, 24, 2357-2361. [CrossRef]

28. Ren, S.; Dawson, R.; Laybourn, A.; Jiang, J.-X.; Khimyak, Y.; Adams, D.J.; Cooper, A.I. Functional conjugated microporous polymers: From 1, 3, 5-benzene to 1,3, 5-triazine. Polym. Chem. 2012, 3, 928-934. [CrossRef]

29. Cooper, A.I. Conjugated microporous polymers. Adv. Mater. 2009, 21, 1291-1295. [CrossRef]

30. Xu, F.; Chen, X.; Tang, Z.; Wu, D.; Fu, R.; Jiang, D. Redox-active conjugated microporous polymers: A new organic platform for highly efficient energy storage. Chem Comm 2014, 50, 4788-4790. [CrossRef]

31. Ben, T.; Ren, H.; Ma, S.; Cao, D.; Lan, J.; Jing, X.; Wang, W.; Xu, J.; Deng, F.; Simmons, J.M. Targeted synthesis of a porous aromatic framework with high stability and exceptionally high surface area. Angew. Chem. 2009, 121, 9621-9624. [CrossRef] 
32. Ren, H.; Ben, T.; Wang, E.; Jing, X.; Xue, M.; Liu, B.; Cui, Y.; Qiu, S.; Zhu, G. Targeted synthesis of a 3D porous aromatic framework for selective sorption of benzene. Chem Comm 2010, 46, 291-293. [CrossRef] [PubMed]

33. Ben, T.; Pei, C.; Zhang, D.; Xu, J.; Deng, F.; Jing, X.; Qiu, S. Gas storage in porous aromatic frameworks (PAFs). Energy Environ. Sci. 2011, 4, 3991-3999.

34. Monnereau, L.; Nieger, M.; Muller, T.; Bräse, S. Tetrakis-(4-thiyphenyl) methane: Origin of a Reversible 3D-Homopolymer. Adv. Funct. Mater. 2014, 24, 1054-1058.

35. Dawson, R.; Ratvijitvech, T.; Corker, M.; Laybourn, A.; Khimyak, Y.Z.; Cooper, A.I.; Adams, D.J. Microporous copolymers for increased gas selectivity. Polym. Chem. 2012, 3, 2034-2038. [CrossRef]

36. Li, S.; Huo, F. Metal-organic framework composites: From fundamentals to applications. Nanoscale 2015, 7, 7482-7501. [CrossRef]

37. Collins, D.J.; Zhou, H.-C. Hydrogen storage in metal-organic frameworks. J. Mater. Chem. 2007, 17, 3154-3160.

38. Van den Berg, A.W.; Areán, C.O. Materials for hydrogen storage: Current research trends and perspectives. ChemComm 2008, 6, 668-681.

39. Mueller, U.; Schubert, M.; Teich, F.; Puetter, H.; Schierle-Arndt, K.; Pastre, J. Metal-organic frameworks-Prospective industrial applications. J. Mater. Chem. 2006, 16, 626-636.

40. Pan, L.; Olson, D.H.; Ciemnolonski, L.R.; Heddy, R.; Li, J. Separation of hydrocarbons with a microporous metal-organic framework. Angew. Chem. Int. Ed. 2006, 45, 616-619. [CrossRef]

41. Horcajada, P.; Chalati, T.; Serre, C.; Gillet, B.; Sebrie, C.; Baati, T.; Eubank, J.F.; Heurtaux, D.; Clayette, P.; Kreuz, C. Porous metal-organic-framework nanoscale carriers as a potential platform for drug delivery and imaging. Nat. Mater. 2010, 9, 172-178. [CrossRef]

42. Khutia, A.; Janiak, C. Programming MIL-101Cr for selective and enhanced $\mathrm{CO}_{2}$ adsorption at low pressure by postsynthetic amine functionalization. Dalton Trans. 2014, 43, 1338-1347. [CrossRef]

43. Botas, J.A.; Calleja, G.; Sánchez-Sánchez, M.; Orcajo, M.G. Cobalt doping of the MOF-5 framework and its effect on gas-adsorption properties. Langmuir 2010, 26, 5300-5303. [CrossRef]

44. Liu, Q.; Ding, Y.; Liao, Q.; Zhu, X.; Wang, H.; Yang, J. Fast synthesis of Al fumarate metal-organic framework as a novel tetraethylenepentamine support for efficient $\mathrm{CO}_{2}$ capture. Colloids Surf. A Physicochem. Eng. Asp. 2019, 579, 123645. [CrossRef]

45. Chen, C.; Kim, J.; Park, D.-W.; Ahn, W.-S. Ethylenediamine grafting on a zeolite-like metal organic framework (ZMOF) for $\mathrm{CO}_{2}$ capture. Mater. Lett. 2013, 106, 344-347. [CrossRef]

46. Le, Y.; Guo, D.; Cheng, B.; Yu, J. Amine-functionalized monodispersed porous silica microspheres with enhanced $\mathrm{CO}_{2}$ adsorption performance and good cyclic stability. J. Colloid Interface Sci. 2013, 408, 173-180. [CrossRef]

47. Furukawa, H.; Cordova, K.E.; O'Keeffe, M.; Yaghi, O.M. The chemistry and applications of metal-organic frameworks. Science 2013, 341. [CrossRef]

48. Lu, W.; Wei, Z.; Gu, Z.-Y.; Liu, T.-F.; Park, J.; Park, J.; Tian, J.; Zhang, M.; Zhang, Q.; Gentle, T., III. Tuning the structure and function of metal-organic frameworks via linker design. Chem. Soc. Rev. 2014, 43, 5561-5593. [CrossRef] [PubMed]

49. Stock, N.; Biswas, S. Synthesis of metal-organic frameworks (MOFs): Routes to various MOF topologies, morphologies, and composites. Chem. Rev. 2012, 112, 933-969. [CrossRef]

50. Lee, Y.-R.; Kim, J.; Ahn, W.-S. Synthesis of metal-organic frameworks: A mini review. Korean J. Chem. Eng. 2013, 30, 1667-1680. [CrossRef]

51. Kashyap, A.; Singh, N.K.; Soni, M.; Soni, A. Deposition of Thin Films by Chemical Solution-Assisted Techniques. In Chemical Solution Synthesis for Materials Design and Thin Film Device Applications; Elsevier: Amsterdam, The Netherlands, 2021; pp. 79-117.

52. Nunes, D.; Pimentel, A.; Santos, L.; Barquinha, P.; Pereira, L.; Fortunato, E.; Martins, R. Synthesis, Design, and Morphology of Metal Oxide Nanostructures. In Metal Oxide Nanostructures; Elsevier: Amsterdam, The Netherlands, 2019; pp. 21-57.

53. Zhou, Y.; Han, L. Recent advances in naphthalenediimide-based metal-organic frameworks: Structures and applications. Coord. Chem. Rev. 2020, 430, 213665. [CrossRef]

54. Chen, C.; Zhang, M.; Zhang, W.; Bai, J. Stable amide-functionalized metal-organic framework with highly selective $\mathrm{CO}_{2}$ adsorption. Inorg. chem. 2019, 58, 2729-2735. [CrossRef] [PubMed]

55. Wang, G.; Leus, K.; Zhao, S.; Van Der Voort, P. Newly designed covalent triazine framework based on novel N-heteroaromatic building blocks for efficient $\mathrm{CO}_{2}$ and $\mathrm{H}_{2}$ capture and storage. ACS Appl. Mater. Interfaces 2017, 10, 1244-1249. [CrossRef]

56. Suresh, V.M.; Bonakala, S.; Atreya, H.S.; Balasubramanian, S.; Maji, T.K. Amide functionalized microporous organic polymer (Am-MOP) for selective $\mathrm{CO}_{2}$ sorption and catalysis. ACS Appl. Mater. Interfaces 2014, 6, 4630-4637. [CrossRef] [PubMed]

57. Dubey, P.; Kumar, C.R.; Babu, B. Solid phase synthesis of benzimidazole ketones and benzimidazole chalcones under solvent-free conditions. Indian J. Chem. 2003, 35, 3128-3130. [CrossRef]

58. Dubey, P.; Naidu, A.; Kumar, C.R. Studies on syntheses of 1-alkyl-2-substitutedthiazolylbenzimidazoles. Indian J. Chem. 2003, 42B, 931-934. [CrossRef]

59. Ramaiah, K.; Dubey, P.; Ramanatham, J.; Kumar, C.R.; Grossert, J. Benzimidazolium dichromates: Efficient reagents for selective oxidation of alcohols to carbonyl compounds. Indian J. Chem. 2003, 42B, 1765-1767. [CrossRef]

60. Dubey, P.; Kumar, C.R.; Reddy, P. Syntheses of 1-alkyl-2-(substituted-2-pyridyl) benzimidazoles. Indian J. Chem. 2003, 42B, 2115-2118. [CrossRef]

61. Dubey, P.; Naidu, A.; Kumar, C.R.; Reddy, P. Preparation of 4-(1-alkyl-benzo [d] imidazole-2-yl)-2-phenyl-2, 3 dihydrobenzo (b) $[1,4]$ thiazepines. Indian J. Chem. 2003, 42B, 1701-1705. [CrossRef] 
62. Dubey, P.; Kumar, R.; Kumar, C.R.; Grossert, J.; Hooper, D. Condensation of o-phenylenediamine with cinnamic acids. Synth. Commun. 2001, 31, 3439-3446. [CrossRef]

63. Lemaire, P.C.; Lee, D.T.; Zhao, J.; Parsons, G.N. Reversible low-temperature metal node distortion during atomic layer deposition of $\mathrm{Al}_{2} \mathrm{O}_{3}$ and $\mathrm{TiO}_{2}$ on UiO-66- $\mathrm{NH}_{2}$ metal-organic framework crystal surfaces. ACS Appl. Mater. Interfaces 2017, 9, 22042-22054. [CrossRef]

64. Wang, Y.; Cao, W.; Wang, L.; Zhuang, Q.; Ni, Y. Electrochemical determination of 2, 4, 6-trinitrophenol using a hybrid film composed of a copper-based metal organic framework and electroreduced graphene oxide. Microchim. Acta 2018, 185, 1-9. [CrossRef]

65. Nivetha, R.; Sajeev, A.; Paul, A.M.; Gothandapani, K.; Gnanasekar, S.; Jacob, G.; Sellappan, R.; Raghavan, V.; Pitchaimuthu, S.; Jeong, S.K.; et al. Cu based Metal Organic Framework (Cu-MOF) for electrocatalytic hydrogen evolution reaction. Mater. Res. Express. 2020, 7, 114001. [CrossRef]

66. Yang, A.; Li, P.; Zhong, J. Facile preparation of low-cost HKUST-1 with lattice vacancies and high-efficiency adsorption for uranium. RSC Adv. 2019, 9, 10320-10325. [CrossRef]

67. Mahdipoor, H.R.; Halladj, R.; Babakhani, E.G.; Amjad-Iranagh, S.; Ahari, J.S. Synthesis, characterization, and $\mathrm{CO}_{2}$ adsorption properties of metal organic framework Fe-BDC. RSC Adv. 2021, 11, 5192-5203. [CrossRef]

68. Torres, N.; Galicia, J.; Plasencia, Y.; Cano, A.; Echevarría, F.; Desdin-Garcia, L.; Reguera, E.J.C.; Physicochemical, S.A.; Aspects, E. Implications of structural differences between Cu-BTC and Fe-BTC on their hydrogen storage capacity. Colloids Surf. A Physicochem. Eng. Asp 2018, 549, 138-146. [CrossRef]

69. Hindocha, S.; Poulston, S. Study of the scale-up, formulation, ageing and ammonia adsorption capacity of MIL-100 (Fe), Cu-BTC and CPO-27 (Ni) for use in respiratory protection filters. Faraday Discuss. 2017, 201, 113-125. [CrossRef]

70. Chen, M.-L.; Zhou, S.-Y.; Xu, Z.; Ding, L.; Cheng, Y.-H. Metal-organic frameworks of MIL-100 (Fe, Cr) and MIL-101 (Cr) for aromatic amines adsorption from aqueous solutions. Molecules 2019, 24, 3718. [CrossRef]

71. Simonsson, I.; Gärdhagen, P.; Andrén, M.; Tam, P.L.; Abbas, Z. Experimental investigations into the irregular synthesis of iron (iii) terephthalate metal-organic frameworks MOF-235 and MIL-101. Dalton Trans. 2021, 50, 4976-4985. [CrossRef]

72. Israr, F.; Chun, D.; Kim, Y.; Kim, D.K. High yield synthesis of Ni-BTC metal-organic framework with ultrasonic irradiation: Role of polar aprotic DMF solvent. Ultrason. Sonochem. 2016, 31, 93-101. [CrossRef]

73. Li, X.; Liu, H.; Jia, X.; Li, G.; An, T.; Gao, Y. Novel approach for removing brominated flame retardant from aquatic environments using $\mathrm{Cu}$ /Fe-based metal-organic frameworks: A case of hexabromocyclododecane (HBCD). Sci. Total Environ. 2018, 621, 1533-1541. [CrossRef]

74. Cheedarala, R.K.; Park, E.J.; Park, Y.B.; Park, H.W. Highly wettable CuO: Graphene oxide core-shell porous nanocomposites for enhanced critical heat flux. Phys. Status Solidi B 2015, 212, 1756-1766. [CrossRef]

75. Nahian, S.A.; Cheedarala, R.K.; Ahn, K.K. A study of sustainable green current generated by the fluid-based triboelectric nanogenerator (FluTENG) with a comparison of contact and sliding mode. Nano Energy 2017, 38, 447-456. [CrossRef]

76. Hadjiivanov, K.I.; Panayotov, D.A.; Mihaylov, M.Y.; Ivanova, E.Z.; Chakarova, K.K.; Andonova, S.M.; Drenchev, N.L. Power of infrared and raman spectroscopies to characterize metal-organic frameworks and investigate their interaction with guest molecules. Chem. Rev. 2020, 121, 1286-1424. [CrossRef]

77. Autie-Castro, G.; Autie, M.; Rodríguez-Castellón, E.; Aguirre, C.; Reguera, E. Cu-BTC and Fe-BTC metal-organic frameworks: Role of the materials structural features on their performance for volatile hydrocarbons separation. Colloids Surf. A Physicochem. Eng. Asp. 2015, 481, 351-357. [CrossRef]

78. Gopi, S.; Al-Mohaimeed, A.M.; Al-onazi, W.A.; Elshikh, M.S.; Yun, K. Metal organic framework-derived Ni-Cu bimetallic electrocatalyst for efficient oxygen evolution reaction. J. King Saud Univ. Sci. 2021, 33, 101379. [CrossRef]

79. Salama, R.S.; El-Hakama, S.A.; Samraa, S.E.; El-Dafrawya, S.M.; Ahmeda, A.I. Adsorption, equilibrium and kinetic studies on the removal of methyl orange dye from aqueous solution by using of copper metal organic framework (Cu-BDC). Int. J. Modern Chem. 2018, 10, 195-207.

80. Andonova, S.; Ivanova, E.; Yang, J.; Hadjiivanov, K. Adsorption Forms of $\mathrm{CO}_{2}$ on MIL-53 (Al) and MIL-53 (Al)-OH x As Revealed by FTIR Spectroscopy. J. Phys. Chem. C 2017, 121, 18665-18673. [CrossRef]

81. Cheedarala, R.K.; Ahn, K.K. Double characteristic BNO-SPI-TENGs for robust contact electrification by vertical contact separation mode through ion and electron charge transfer. Nano Energy 2018, 44, 430-437. [CrossRef]

82. Cheedarala, R.K.; Parvez, A.N.; Ahn, K.K. Electric impulse spring-assisted contact separation mode triboelectric nanogenerator fabricated from polyaniline emeraldine salt and woven carbon fibers. Nano Energy 2018, 53, 362-372. [CrossRef]

83. Peedikakkal, A.M.P.; Aljundi, I.H. Mixed-Metal Cu-BTC Metal-Organic Frameworks as a Strong Adsorbent for Molecular Hydrogen at Low Temperatures. ACS Omega 2020, 5, 28493-28499. [CrossRef]

84. Peng, Y.; Huang, H.; Zhang, Y.; Kang, C.; Chen, S.; Song, L.; Liu, D.; Zhong, C. A versatile MOF-based trap for heavy metal ion capture and dispersion. Nat. Commun. 2018, 9, 1-9. [CrossRef]

85. Ongari, D.; Tiana, D.; Stoneburner, S.J.; Gagliardi, L.; Smit, B. Origin of the Strong Interaction between Polar Molecules and Copper (II) Paddle-Wheels in Metal Organic Frameworks. J. Phys. Chem. 2017, 121, 15135-15144. [CrossRef]

86. Mishra, P.; Edubilli, S.; Mandal, B.; Gumma, S. Adsorption of $\mathrm{CO}_{2}, \mathrm{CO}, \mathrm{CH}_{4}$ and $\mathrm{N}_{2}$ on DABCO based metal organic frameworks. Microporous Mesoporous Mater. 2013, 169, 75-80. [CrossRef] 
87. Zhang, Z.; Xian, S.; Xi, H.; Wang, H.; Li, Z. Improvement of $\mathrm{CO}_{2}$ adsorption on ZIF-8 crystals modified by enhancing basicity of surface. Chem. Eng. Sci. 2011, 66, 4878-4888. [CrossRef]

88. Munusamy, K.; Sethia, G.; Patil, D.V.; Rallapalli, P.B.S.; Somani, R.S.; Bajaj, H.C. Sorption of carbon dioxide, methane, nitrogen and carbon monoxide on MIL-101 (Cr): Volumetric measurements and dynamic adsorption studies. Chem. Eng. J. 2012, 195, 359-368. [CrossRef]

89. Saha, D.; Bao, Z.; Jia, F.; Deng, S. Adsorption of $\mathrm{CO}_{2}, \mathrm{CH}_{4}, \mathrm{~N}_{2} \mathrm{O}$, and $\mathrm{N}_{2}$ on MOF-5, MOF-177, and zeolite 5A. Environ. Sci. Technol. 2010, 44, 1820-1826. [CrossRef]

90. Flaig, R.W.; Osborn Popp, T.M.; Fracaroli, A.M.; Kapustin, E.A.; Kalmutzki, M.J.; Altamimi, R.M.; Fathieh, F.; Reimer, J.A.; Yaghi, O.M. The chemistry of $\mathrm{CO}_{2}$ capture in an amine-functionalized metal-organic framework under dry and humid conditions. J. Am. Chem. Soc. 2017, 139, 12125-12128. [CrossRef]

91. Lee, Y.G.; Moon, H.R.; Cheon, Y.E.; Suh, M.P. A comparison of the $\mathrm{H}_{2}$ sorption capacities of isostructural metal-organic frameworks with and without accessible metal sites: $[\{\mathrm{Zn} 2(\mathrm{abtc})(\mathrm{dmf}) 2\} 3]$ and $[\{\mathrm{Cu} 2(\mathrm{abtc})(\mathrm{dmf}) 2\} 3]$ versus $[\{\mathrm{Cu} 2(\mathrm{abtc})\} 3]$. Angew. Chem. 2008, 120, 7855-7859. [CrossRef]

92. Sumida, K.; Horike, S.; Kaye, S.S.; Herm, Z.R.; Queen, W.L.; Brown, C.M.; Grandjean, F.; Long, G.J.; Dailly, A.; Long, J.R. Hydrogen storage and carbon dioxide capture in an iron-based sodalite-type metal-organic framework (Fe-BTT) discovered via high-throughput methods. Chem. Sci. 2010, 1, 184-191. [CrossRef]

93. Hou, L.; Shi, W.-J.; Wang, Y.-Y.; Guo, Y.; Jin, C.; Shi, Q.-Z. A rod packing microporous metal-organic framework: Unprecedented ukv topology, high sorption selectivity and affinity for $\mathrm{CO}_{2}$. Chem Comm 2011, 47, 5464-5466. [CrossRef]

94. Mallick, A.; Saha, S.; Pachfule, P.; Roy, S.; Banerjee, R. Selective $\mathrm{CO}_{2}$ and $\mathrm{H}_{2}$ adsorption in a chiral magnesium-based metal organic framework (Mg-MOF) with open metal sites. J. Mater. Chem. 2010, 20, 9073-9080. [CrossRef]

95. Zhang, Z.; Xiang, S.; Rao, X.; Zheng, Q.; Fronczek, F.R.; Qian, G.; Chen, B. A rod packing microporous metal-organic framework with open metal sites for selective guest sorption and sensing of nitrobenzene. ChemComm 2010, 46, 7205-7207. [CrossRef]

96. Kim, S.-N.; Kim, J.; Kim, H.-Y.; Cho, H.-Y.; Ahn, W.-S. Adsorption/catalytic properties of MIL-125 and NH2-MIL-125. Catal. Today 2013, 204, 85-93. [CrossRef]

97. Qin, J.-S.; Du, D.-Y.; Li, W.-L.; Zhang, J.-P.; Li, S.-L.; Su, Z.-M.; Wang, X.-L.; Xu, Q.; Shao, K.-Z.; Lan, Y.-Q. N-rich zeolite-like metal-organic framework with sodalite topology: High $\mathrm{CO}_{2}$ uptake, selective gas adsorption and efficient drug delivery. Chem. Sci. 2012, 3, 2114-2118. [CrossRef]

98. Zhang, G.; Wei, G.; Liu, Z.; Oliver, S.R.; Fei, H. A robust sulfonate-based metal-organic framework with permanent porosity for efficient $\mathrm{CO}_{2}$ capture and conversion. Chem. Mater. 2016, 28, 6276-6281. [CrossRef]

99. Liao, P.-Q.; Zhou, D.-D.; Zhu, A.-X.; Jiang, L.; Lin, R.-B.; Zhang, J.-P.; Chen, X.-M. Strong and dynamic $\mathrm{CO}_{2}$ sorption in a flexible porous framework possessing guest chelating claws. J. Am. Chem. Soc. 2012, 134, 17380-17383. [CrossRef]

100. Jiang, Z.-R.; Wang, H.; Hu, Y.; Lu, J.; Jiang, H.-L. Polar group and defect engineering in a metal-organic framework: Synergistic promotion of carbon dioxide sorption and conversion. ChemSusChem 2015, 8, 878-885. [CrossRef]

101. Debatin, F.; Thomas, A.; Kelling, A.; Hedin, N.; Bacsik, Z.; Senkovska, I.; Kaskel, S.; Junginger, M.; Müller, H.; Schilde, U. In Situ Synthesis of an Imidazolate-4-amide-5-imidate Ligand and Formation of a Microporous Zinc-Organic Framework with $\mathrm{H}_{2}$-and $\mathrm{CO}_{2}$-Storage Ability. Angew. Chem. 2010, 122, 1280-1284. [CrossRef]

102. Prasad, T.K.; Suh, M.P. Control of Interpenetration and Gas-Sorption Properties of Metal-Organic Frameworks by a Simple Change in Ligand Design. Chem. Eur. J. 2012, 18, 8673-8680. [CrossRef]

103. Zheng, S.-T.; Bu, J.T.; Li, Y.; Wu, T.; Zuo, F.; Feng, P.; Bu, X. Pore space partition and charge separation in cage-within-cage indium-Organic frameworks with high $\mathrm{CO}_{2}$ uptake. J. Am. Chem. Soc. 2010, 132, 17062-17064. [CrossRef]

104. Choi, H.S.; Suh, M.P. Highly selective $\mathrm{CO}_{2}$ capture in flexible 3D coordination polymer networks. Angew. Chem. Int. Ed. 2009, 48, 6865-6869. [CrossRef]

105. Hu, Z.; Zhang, K.; Zhang, M.; Guo, Z.; Jiang, J.; Zhao, D. A Combinatorial Approach towards Water-Stable Metal-Organic Frameworks for Highly Efficient Carbon Dioxide Separation. ChemSusChem 2014, 7, 2791-2795. [CrossRef]

106. Park, J.; Yuan, D.; Pham, K.T.; Li, J.-R.; Yakovenko, A.; Zhou, H.-C. Reversible alteration of $\mathrm{CO}_{2}$ adsorption upon photochemical or thermal treatment in a metal-organic framework. J. Am. Chem. Soc. 2012, 134, 99-102. [CrossRef]

107. Demessence, A.; D'Alessandro, D.M.; Foo, M.L.; Long, J.R. Strong $\mathrm{CO}_{2}$ binding in a water-stable, triazolate-bridged metal-organic framework functionalized with ethylenediamine. J. Am. Chem. Soc. 2009, 131, 8784-8786. [CrossRef]

108. Park, H.J.; Cheon, Y.E.; Suh, M.P. Post-Synthetic Reversible Incorporation of Organic Linkers into Porous Metal-Organic Frameworks through Single-Crystal-to-Single-Crystal Transformations and Modification of Gas-Sorption Properties. Chem. Eur. J. 2010, 16, 11662-11669. [CrossRef]

109. Hong, D.H.; Suh, M.P. Enhancing $\mathrm{CO}_{2}$ Separation Ability of a Metal-Organic Framework by Post-Synthetic Ligand Exchange with Flexible Aliphatic Carboxylates. Chem. Eur. J. 2014, 20, 426-434. [CrossRef]

110. Chandrashekhar, N.; Thomas, B.; Gayathri, V.; Ramanathan, K.; Nanje Gowda, N.M. Synthesis and NMR spectral assignments of novel nitrogen and sulfur heterocyclic compounds. Magn. Reson. Chem. 2008, 46, 769-774. [CrossRef]

111. Xiong, J.-F.; Luo, S.-H.; Huo, J.-P.; Liu, J.-Y.; Chen, S.-X.; Wang, Z.-Y. Design, Synthesis, and Characterization of 1, 3, 5-Tri (1 H-benzo [d] imidazol-2-yl) benzene-Based Fluorescent Supramolecular Columnar Liquid Crystals with a Broad Mesomorphic Range. J. Org. Chem. 2014, 79, 8366-8373. [CrossRef] 
112. Lin, Y.; Kong, C.; Chen, L. Direct synthesis of amine-functionalized MIL-101 (Cr) nanoparticles and application for $\mathrm{CO}_{2}$ capture. RSC Adv. 2012, 2, 6417-6419. [CrossRef]

113. Gaikwad, S.; Kim, S.-J.; Han, S. $\mathrm{CO}_{2}$ capture using amine-functionalized bimetallic MIL-101 MOFs and their stability on exposure to humid air and acid gases. Microporous Mesoporous Mater. 2019, 277, 253-260. [CrossRef]

114. Cao, Y.; Zhao, Y.; Lv, Z.; Song, F.; Zhong, Q. Preparation and enhanced $\mathrm{CO}_{2}$ adsorption capacity of UiO-66/graphene oxide composites. J. Ind. Eng. Chem. 2015, 27, 102-107. [CrossRef]

115. Walton, K.S.; Millward, A.R.; Dubbeldam, D.; Frost, H.; Low, J.J.; Yaghi, O.M.; Snurr, R.Q. Understanding inflections and steps in carbon dioxide adsorption isotherms in metal-organic frameworks. J. Am. Chem. Soc. 2008, 130, 406-407. [CrossRef] [PubMed]

116. Gaikwad, S.; Kim, Y.; Gaikwad, R.; Han, S. Enhanced $\mathrm{CO}_{2}$ capture capacity of amine-functionalized MOF-177 metal organic framework. J. Environ. Chem. Eng. 2021, 9, 105523. [CrossRef] 